\title{
GROUND MEASUREMENTS OF DCMIX 4 PROJECT FULLERENE BASED NANOFLUID
}

\author{
M. MOUNIR BOU-ALI ${ }^{1}$, A. ERRARTE ${ }^{1}$, A. MIALDUN ${ }^{2}$, \\ V. SHEVTSOVA ${ }^{2}$, M. SCHRAML ${ }^{3}$ and W. KÖHLER ${ }^{3}$
${ }^{1}$ Mechanical and Industrial Manufacturing Department, MGEP Mondragon Goi Eskola Politeknikoa, Loramendi 4 Apdo. 23, 20500 Mondragon, Spain
${ }^{2}$ MRC, CP165/62, Université Libre de Bruxelles, Ave. F.D. Roosevelt, 50, B-1050 Brussels, Belgium
${ }^{3}$ Physikalisches Institut, Universität Bayreuth, D-95440 Bayreuth, Germany \\ mbouali@mondragon.edu
}

\begin{abstract}
This work presents first on ground measurements of DCMIX 4 project ternary nanofluid Fullerene, 1,2,3,4tetrahydronaphtalene and Toluene. Transport properties have been measured by Thermogravitational, Optical Digital Interferometry and Optical Beam Deflection techniques for concentration analysed in DCMIX 4 project, which refers to $0.0007-0.60-0.3993$ and other fullerene concentrations around this value. Various thermophysical and optical properties which are necessary to determine thermodiffusion coefficients have been also measured.
\end{abstract}

Keywords: Nanofluid, Fullerene, Ternary mixture, DCMIX project, Thermophysical properties, Transport properties.

\section{Introduction}

During the last decades, thermodiffusion phenomenon has gained great interest in the scientific community due to its appearance in diverse fields, both in natural and industrial processes [1-3]. This phenomenon, describes the separation of concentrations of the components of a mixture in a presence of a thermal gradient.

Due to the increase of interest, a collaborative project was developed with the support of the European Space Agency, DCMIX. This project, which means Diffusion Coefficient Measurements in Ternary MIXtures, consists on the study of the thermodiffusion effect in different multicomponent mixtures. With this aim, SODI installation is employed in the International Space Station (ISS).

This work is settled in the fourth mission of DCMIX project, where for the first time nanofluids are analysed. First DCMIX analysed the ternary mixture THN-IBBnC12, where a benchmark of results was completed [4]. DCMIX 2 analysed the critical mixture composed by Tol-Meth-Ch, which shows an immiscibility gap and negative Soret coefficients for some concentrations [5-6]. Third mission, DCMIX 3, focused on the study of aqueous mixtures such as $\mathrm{H}_{2} \mathrm{O}$-Eth-TEG [7-8]. In this fourth mission, on the one hand Tol-Meth-Ch mixture will be analysed, and on the other nanofluids as $\mathrm{C}_{60}$ -
THN-Tol and Poliestirene-Tol-Ch will be studied. Antares rocket with samples was launched in $17^{\text {th }}$ of November (Figure 1), and samples arrived to the ISS by $19^{\text {th }}$. Experiments will start on December 2018.

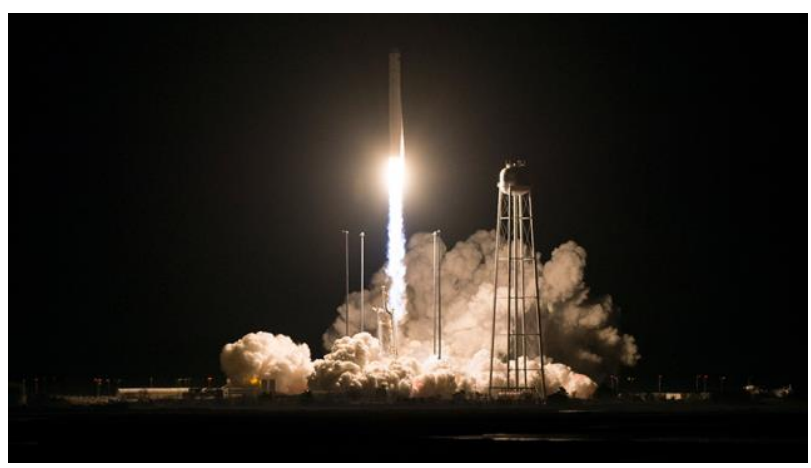

Figure 1: Antares Rocket Launching on morning of $17^{\text {th }}$ November 2018. Picture provided by NASA.

Our work provides new ground results about thermophysical and transport properties of $\mathrm{C}_{60}-\mathrm{THN}-\mathrm{Tol}$ nanofluid mixture for different fullerene concentration around the one studied in the ISS $\left(\mathrm{C}_{60}: 0.0007-\mathrm{THN}\right.$ : 0.6 - Tol: 0.3993).

Section division of the work has been done as follows, first the experimental methodology is described for all participant earth laboratories and ISS, and finally conclusions and discussion is held.

\section{Experimental methodology}

This section describes the technologies used on ground and microgravity conditions for thermophysical, optical, and transport properties determined during this work.

\subsection{Thermophysical and optical properties}

Thermophysical properties are necessary to perform the determination of the thermodiffusion coefficient with the thermogravitational column. For this reason, density, viscosity and thermal expansion have been determined.

An Anton Paar DMA 5000 density meter has been used to measure the density. This device has an accuracy of $5 \cdot 10^{-3} \mathrm{Kg} / \mathrm{m}^{3}$. The same equipment has been used for mass and thermal expansion studies. Thermal expansion 
coefficient is determined by measuring the sample at different temperatures and following the expression (1):

$$
\alpha=-\frac{1}{\rho} \frac{\partial \rho}{\partial T}
$$

Viscosity measurements have been carried out by an Anton Paar AMVn falling ball microviscometer, with an accuracy of $\pm 0.002 \mathrm{~s}$.

On the other hand, refractive indexes and contrast factors have been measured. For this purpose, two different equipment have been used: the Anton Paar RXA 156 refractometer and the Anton Paar Abbemat MW multiwavelength refractometer. The first one measures the refractive index with a $\lambda$ of $589.3 \mathrm{~nm}$. On the other hand, the latter is able to determine it at $\lambda=435.8 \mathrm{~nm}$, $480.0 \mathrm{~nm}, 514.5 \mathrm{~nm}, 546.1 \mathrm{~nm}, 589.3 \mathrm{~nm}, 632.8 \mathrm{~nm}$ and $656.3 \mathrm{~nm}$.

Finally, by measurements of both density and refractive indexes, calibration constants have been calculated in order to be able to determine mixture concentration starting from those parameters.

Further information about techniques in [9].

\subsection{Thermogravitational technique}

Thermodiffusion coefficient determination has been carried out by the thermogravitational technique (TG), where a sample is placed between two vertical walls and a horizontal temperature gradient is established (Figure 2).

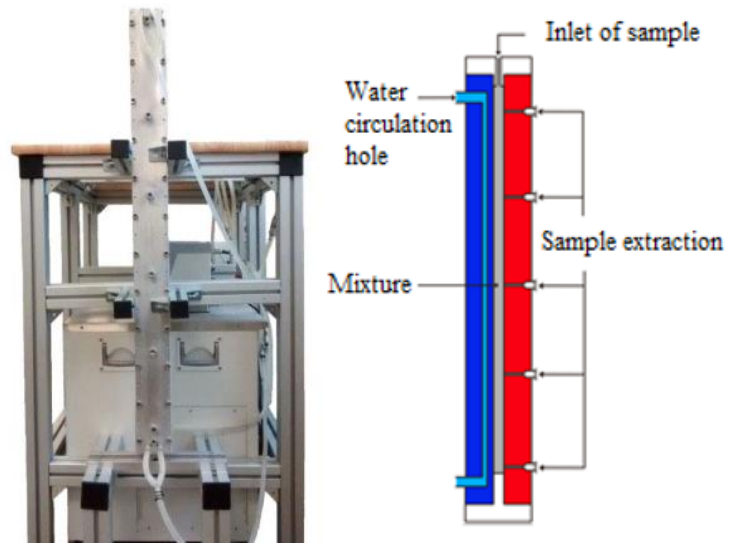

Figure 2: Thermogravitational column and scheme used in this work.

For this study the Large Thermogravitational column has been used with dimensions, $L_{z}=980 \mathrm{~mm}, L_{x}=1.02 \pm$ $0.005 \mathrm{~mm}$ and $L_{y}=50 \mathrm{~mm}$. Following this technique, the concentration along the column is determined. For this purpose extraction of sample is done from 5 different heights of the column and the density and refractive index is measured.

The concentration for each height analysed is determined with the calibration constants obtained from the ternary mixture calibration. Finally, $D_{T}$ coefficients are directly defined by the following expression (2) from [10]:

$D_{T, i}^{\prime}=-\frac{L_{x}^{4}}{504 L_{z}} \frac{\alpha g}{v} \Delta c_{i}$

\subsection{Optical Digital Interferometry (ODI) technique}

This technique developed in the lab of Prof. Shevtsova enables to determine the Soret and diffusion coefficients [11]. The sample is placed in a fused silica cell of $22 \times 22 \times 6.3 \mathrm{~mm}^{3}$. A temperature gradient is applied in vertical direction, where water baths, peltier systems and copper plates are used for its generation. In this installation the top part is heated and the bottom one cooled, generating a vertical concentration distribution across the cell.

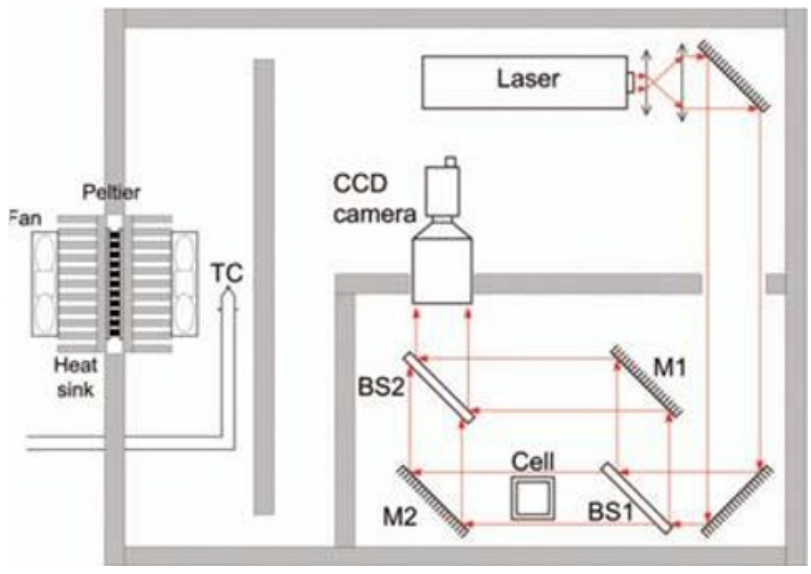

Figure 3: Technical scheme of ODI technique.

An optical analysis method is used by a Mach-Zehnder interferometer as seen in Figure 3. Two lasers of $\lambda=670$ and $925 \mathrm{~nm}$ are used, where the final interferometry patterns are captured by a CCD camera. Coefficient determination is carried out by refractive index analysis, where it is known that changes in refractive index enables to determine the concentration of each of the components.

\subsection{Optical Beam Deflection (OBD) technique}

The OBD technique developed in the lab of Prof. Köhler enables to determine the Soret coefficient in a direct manner and diffusion and thermodiffusion ones by means of numerical solutions [12]. The technique is based on the deflection of a laser that goes through a diffusion cell (see Figure 4).

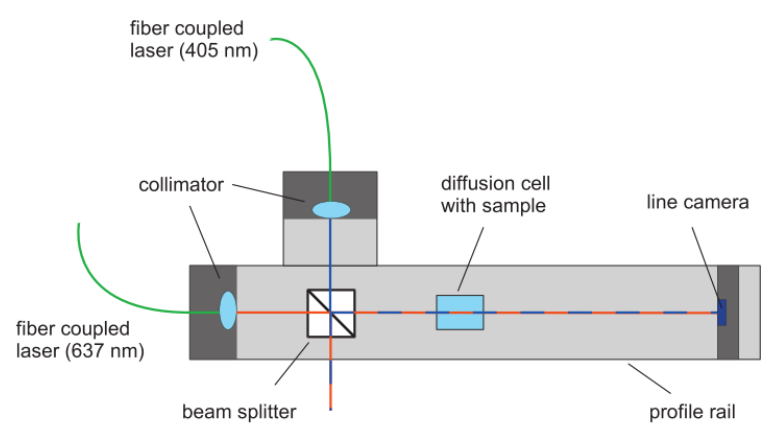

Figure 4: $O B D$ scheme.

For ternary mixtures analysis, the installation consists of two lasers of 405 and $637 \mathrm{~nm}$, a diffusion cell and a camera that detects the deflection of the lasers. As in ODI, a vertical temperature gradient is applied between the top and bottom walls, and a vertical concentration gradient is obtained. As a consequence, a variation of refractive index is detected and recorded by the camera, 
and finally, concentration separation can be obtained from those values.

\subsection{Selected Optical Diagnostic Instrument (SODI)}

SODI is the actual technique used in the International Space station for diffusion, thermodiffusion and Soret coefficients in microgravity conditions [13].

The technique is based on Mach-Zehnder interferometry, where two lasers of 670 and $935 \mathrm{~nm}$ wavelengths are used. There are two optical bridges, one fixed and the other one moving (Figure 5).
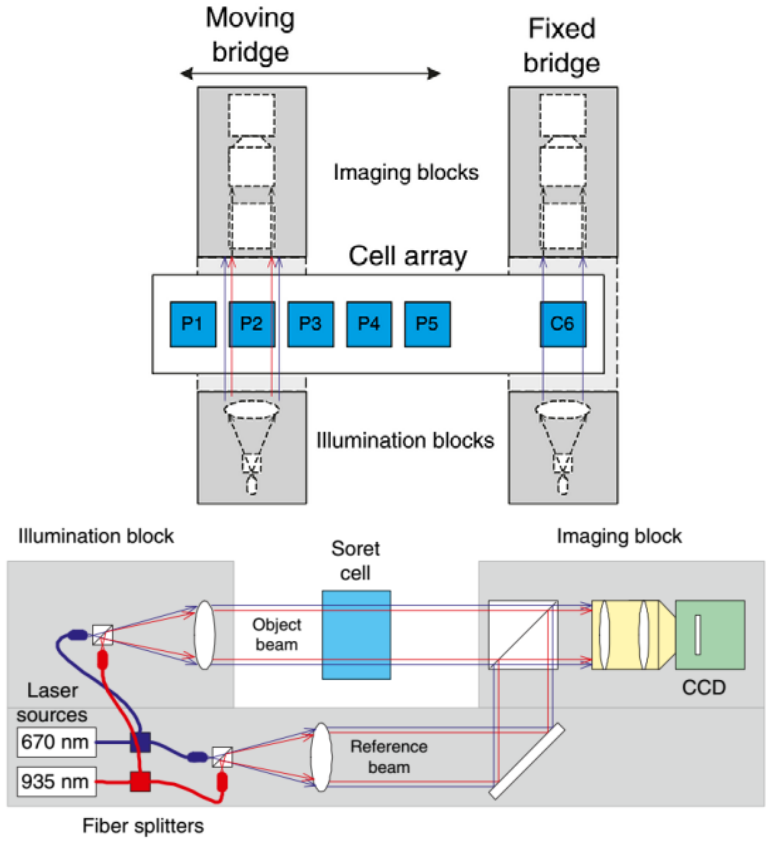

Figure 5: Schemes of SODI installation. Vertical view of all the system and lateral view of the moving bridge.

The fixed one analyses the reference cell using one laser, while the moving one has two lasers to study the rest 5 cells that contain ternary mixtures. Each bridge has two zones, illumination one and imaging one. Same as in ODI, one of the beams of the interferometer goes from the cell while the other acts as reference. Finally, when both beams are unified, the interferometry pattern is generated and recorded by the CCD camera.

\section{Conclusions and discussion}

In this work an overview of techniques that are being used for DCMIX 4 project ternary nanofluid C60-THNTol study are narrated.

Actual state of the project, progress and results will be shown during the Mechanics Congress in Rabat.

\section{Acknowledgements}

This work represents results obtained in the framework of the following projects: FETRAFLU (2018-CIEN000101-01) from Gipuzkoa Program for Science, ATNEMFLU (ESP2017-83544-C3-1-P) of the MINECO, DCMIX (AO-2009-0858/1056) from the European Space Agency, the Research Group Program (IT1009-16) from the Basque Government, Deutsches Zentrum für Luft and Raumfahrt (Grant 50WM1544).

\section{References}

[1] D. Braun and A. Libchaber, "Trapping of DNA by Thermophoretic Depletion and Convection," Phys. Rev. Lett., vol. 89, no. 18, p. 188103, Oct. 2002. K. Ghorayeb and A. Firoozabadi, "Interpretation of the Unusual Fluid Distribution in the Yufutsu GasCondensate Field," SPE Journal,Reservoir Eng. Res. Inst.; Toshiyuki Anraku, Japan Pet. Explor. Co, vol. 8, no. 2, pp. 114-123, 2003.

[3] J. K. Platten, M. M. Bou-Ali, and J. F. Dutrieux, "Enhanced Molecular Separation in Inclined Thermogravitational Columns," J. Phys. Chem. B, vol. 107, no. 42, pp. 11763-11767, Oct. 2003.

[4] M. M. Bou-Ali et al., "Benchmark values for the Soret, thermodiffusion and molecular diffusion coefficients of the ternary mixture tetralin+isobutylbenzene+n-dodecane with 0.8-0.1-0.1 mass fraction," Eur. Phys. J. E, vol. 38, no. 4, pp. 4-9, 2015.

[5] A. Mialdun, I. Ryzhkov, O. Khlybov, T. Lyubimova, and V. Shevtsova, "Measurement of Soret coefficients in a ternary mixture of toluene-methanol-cyclohexane in convection-free environment," J. Chem. Phys., vol. 148, no. 4, p. 044506, Jan. 2018.

[6] E. Lapeira et al., "Transport properties of the binary mixtures of the three organic liquids toluene, methanol, and cyclohexane," J. Chem. Phys., vol. 146, no. 9, 2017.

E. Lapeira, M. M. Bou-Ali, J. A. Madariaga, and C. Santamaría, "Thermodiffusion Coefficients of Water/Ethanol Mixtures for Low Water Mass Fractions," Microgravity Sci. Technol., vol. 28, no. 5, pp. 553-557, 2016.

[8] T. Triller et al., "Thermodiffusion in Ternary Mixtures of Water/Ethanol/Triethylene Glycol: First Report on the DCMIX3-Experiments Performed on the International Space Station," Microgravity Sci. Technol., vol. 30, no. 3, pp. 295-308, May 2018.

[9] J. K. Platten et al., "Benchmark values for the Soret, thermal diffusion and diffusion coefficients of three binary organic liquid mixtures," Philos. Mag., vol. 83, no. 17-18, pp. 1965-1971, Jan. 2003.

[10] B. A. S. M. Mounir and J. K. Platten, "Metrology of the thermodiffusion coefficients in a ternary system," J. Non-Equilibrium Thermodyn., vol. 30, no. 4, pp. 385-399, 2005.

[11] A. Mialdun, J.-C. Legros, V. Yasnou, V. Sechenyh, and V. Shevtsova, "Contribution to the benchmark for ternary mixtures: Measurement of the Soret, diffusion and thermodiffusion coefficients in the ternary mixture $\mathrm{THN} / \mathrm{IBB} / \mathrm{nC} 12$ with $0.8 / 0.1 / 0.1$ mass fractions in ground and orbital laboratories," Eur. Phys. J. E, vol. 38, no. 4, p. 27, Apr. 2015.

[12] A. Königer, H. Wunderlich, and W. Köhler, "Measurement of diffusion and thermal diffusion in ternary fluid mixtures using a two-color optical beam deflection technique," J. Chem. Phys., vol. 132, no. 17, p. 174506, May 2010.

[13] A. Mialdun, C. Minetti, Y. Gaponenko, V. Shevtsova, and F. Dubois, "Analysis of the Thermal Performance of SODI Instrument for DCMIX Configuration," Microgravity Sci. Technol., vol. 25, no. 1, pp. 83-94, Feb. 2013. 